\title{
Programa Especial Adolescente 2007 para alunos em de 14 e 15 anos de idades \\ um estudo de caso etnográfico em uma Escola da Rede Pública Municipal do Rio de Janeiro.
}

\author{
Carmem Lúcia Guimarães de Mattos
}

Adriana Maria Ribeiro Gil Ferreira

\section{SciELO Books / SciELO Livros / SciELO Libros}

MATTOS, CLG., and FERREIRA, AMRG. Programa Especial Adolescente 2007 para alunos em de 14 e 15 anos de idades: um estudo de caso etnográfico em uma Escola da Rede Pública Municipal do Rio de Janeiro. In MATTOS, CLG., and CASTRO, PA., orgs. Etnografia e educação: conceitos e usos [online]. Campina Grande: EDUEPB, 2011. pp. 173-194. ISBN 978-85-7879-190-2. Available from SciELO Books < http://books.scielo.org>.

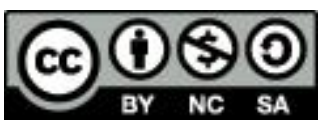

All the contents of this work, except where otherwise noted, is licensed under a Creative Commons Attribution-Non Commercial-ShareAlike 3.0 Unported.

Todo o conteúdo deste trabalho, exceto quando houver ressalva, é publicado sob a licença Creative Commons Atribuição Uso Não Comercial - Partilha nos Mesmos Termos 3.0 Não adaptada.

Todo el contenido de esta obra, excepto donde se indique lo contrario, está bajo licencia de la licencia Creative Commons Reconocimento-NoComercial-CompartirIgual 3.0 Unported. 


\section{Programa Especial Adolescente 2007 para alunos em de 14 e 15 anos de idades: um estudo de caso etnográfico em uma Escola da Rede Pública Municipal do Rio de Janeiro.}

Carmen Lúcia Guimarães de Mattos Adriana Maria Ribeiro Gil Ferreira

Este capítulo apresenta um estudo de caso etnográfico sobre o Projeto Especial Adolescentes (PEA) em uma escola da Rede de Ensino Infantil e Fundamental da Secretaria Municipal de Educação do Rio de Janeiro (SME/RJ). Os dados, coletados em 2007, compõe o acervo da pesquisa 'Imagens Etnográficas da Inclusão Escolar: o fracasso escolar na perspectiva do aluno', coordenada por Mattos (2008) e desenvolvida pela equipe de pesquisadores do Núcleo de Etnografia em Educação (netEDU) da Universidade do Rio de Janeiro (UERJ) no período de 2005 a 2008.

O estudo de caso etnográfico foi incluído nas análises dos dados que compõe parte do trabalho de conclusão de curso em Pedagogia da Faculdade de Educação (FE) da UERJ de Ferreira orientada por Mattos. O objetivo do trabalho de Ferreira foi analisar e interpretar o significado para os atores sociais da criação, implementação, desenvolvimento e finalização do PEA. Parte dos resultados de Ferreira (idem) foi selecionado com o objetivo de estudar a natureza das atividades e das interações entre os alunos e o professor da Classe do PEA. Assim, este capítulo contém análises descritivas e críticas ao PEA, envolvendo particularidades do atendimento aos adolescentes atendidos pela escola participante do estudo assim como dos atores sociais que colaboraram com a pesquisa. 


\section{Sobre o Projeto Especial Adolescente (PEA)}

Em 2007, a SME/RJ modificou o sistema de organização escolar em sua rede de ensino e ampliou o Ciclo de Formação, antes limitado ao $1^{\circ}$ Ciclo, para todo o Ensino Fundamental. O documento oficial com indicações para a promoção desta mudança estabeleceu o seguinte:

No que se refere à estruturação das turmas, tomou, como referencial, as fases do desenvolvimento humano: $1^{\circ}$ Ciclo de Formação: infância (seis a oito anos); $2^{\circ}$ Ciclo de Formação: pré-adolescência (9 a 11 anos); e $3^{\circ}$ Ciclo de Formação: adolescência (12 a 14 anos). Para os adolescentes, com 14 e 15 anos, oriundos das turmas de Progressão e que ainda não consolidaram o processo de leitura e escrita, foi criado o "Projeto Adolescentes", coordenado pela Diretoria de Ensino Fundamental do E/DGED, em parceria com as Divisões de Educação das Coordenadorias Regionais. Este projeto estabelece atendimento aos alunos em horário integral, com atividades culturais e de apoio à aprendizagem, além da formação continuada para os professores e acompanhamento efetivo do Nível Central da SME e do Nível Intermediário - as Coordenadorias Regionais de Educação (CREs) (SME/RJ, 2007 p.11).

O documento salienta que esta forma de organização deve ser associada a outras estratégias que deveriam ser estabelecidas pelas escolas para a 'estruturação das turmas' com o objetivo de atender aos alunos que apresentassem defasagem idade-série, de forma a garantir a 'adequação pedagógica às necessidades educacionais' desse grupo de alunos. Estabelece ainda que, dentre essas estratégias a ênfase deveria ser dada para: a recuperação paralela, o apoio pedagógico, o reagrupamento e os centros de estudos. No documento essa orientação é a seguinte: 
Recuperação paralela - A recuperação paralela é um mecanismo de apoio determinado pela própria LDB, dirigida aos alunos que apresentem dificuldades ou que tenham ingressado tardiamente na escola. Cabe ao professor regente a orientação específica, adequada às necessidades educacionais de cada aluno, possibilitando, através de novos caminhos pedagógicos, novas estratégias com 0

Apoio pedagógico - Caso persistam as dificuldades de aprendizagem, o aluno poderá ser atendido pelo professor de apoio pedagógico que trabalhará em conjunto com o professor regente, tanto na elaboração do planejamento e realização de atividades, quanto no processo avaliativo.

Reagrupamento - A partir do mapeamento das habilidades de professores e alunos e do levantamento das necessidades educacionais destes últimos, a escola deverá realizar, o reagrupamento de seus alunos. Esta ação pressupõe um trabalho coletivo, em que todos os professores são responsáveis pela aprendizagem de todos os alunos. Atividades diversificadas e específicas para cada grupamento deverão possibilitar a inclusão e o desenvolvimento de todos.

Centros de Estudos - Os Centros de Estudos, tanto para alunos, como para professores, se constituem em espaços privilegiados da aprendizagem coletiva no sistema ciclado (SME/RJ, 2007 p.12).

Com a previsão de término no mesmo ano, o PEA visava o atendimento dos alunos com idades entre 14 e 15 anos oriundos de escolas da Rede Municipal que faziam parte da extinta Classe de Progressão no ano de 2006 (SME/RJ, 2008). Os alunos que estavam nas Classes de Progressão e que ainda não haviam consolidado o processo de leitura e escrita, deveriam ser separados, reagrupados e distribuídos nas 38 escolas onde foram 
criadas as Classes de Projeto, formando no total 42 turmas. Nelas, o atendimento aos alunos se daria em horário ampliado, com atividades culturais e de apoio à aprendizagem, além da formação continuada para os professores e acompanhamento à nível central por especialistas da SME/RJ e à nível intermediário pelas CREs.

Nessas classes os alunos deveriam receber uma formação de caráter acelerado e durante o período de um ano seriam avaliados, através de relatórios de acompanhamento pelo professor regente da turma. De acordo com os rendimentos, os alunos seriam reinseridos nos agrupamentos de classes regulares, que fossem mais apropriadas à sua faixa etária (SME/RJ, 2007).

Destaca-se que a avaliação desses alunos de acordo com a Resolução n 776 (SME/RJ, 2003), deveria seguir o que está estabelecido no Art. $5^{\circ}$ "A avaliação dos alunos das Classes Especiais deverá ser expressa nos relatórios de observação inicial e de acompanhamento". Portanto, nessa avaliação, não haveria notas ou conceitos, ela seria baseada na análise do desenvolvimento do aluno incluindo avanços e recuos percebidos pelo professor. Estes movimentos deveriam ser descritos em relatório detalhado que seria anexado ao Registro de Classe. Este Registro é um documento oficial que serve como fonte de informação sobre a vida do aluno e deve estar sempre atualizado e corretamente preenchido em todos os seus itens. De acordo com a SME, a guarda desses Registros é de responsabilidade da Direção da escola e está sujeito a fiscalização não podendo ser retirado da Unidade e nem mantido em local inadequado (SME/RJ, 2007). Neles deveria constar todo e qualquer recurso interposto pela escola ou pelos pais e responsáveis em relação ao aluno.

A turma deveria ser regida por apenas um professor que seria escolhido, pela própria escola, para atuar no Projeto, embora a turma fosse atendida em horário integral: das $7 \mathrm{~h}$ às $15 \mathrm{~h}$, diferente das demais classes desta escola. O professor regeria a turma em caráter exclusivo e ainda atenderia a pequenos grupos, duas vezes por semana, em horário extra, das 15 às $17 \mathrm{~h}$. 
O Projeto Especial Adolescentes 2007 previa um trabalho de formação continuada e em serviço para os professores regentes. Os professores deveriam se reunir com a Equipe Gestora do Projeto todas as sextas-feiras. Neste dia os alunos deveriam ser liberados. A equipe gestora era formada por membros da Diretoria de Educação Fundamental (DEF/SME/RJ). Sua função era orientar e apoiar os professores durante o período em que o PEA estivesse em funcionamento. $O$ trabalho de formação continuada era organizado através de Centros de Estudo, com o planejamento coletivo e a organização de atividades culturais, orientadas pela equipe gestora como previsto pela Ementa do PEA (SME/RJ, 2007).

Destaca-se, ainda, que a Diretoria de Ensino Fundamental regida pelo E/DGED previa como um dos objetivos específicos do Projeto a contribuição para a atuação pedagógica dos professores regentes, em consonância com a organização dos Ciclos de Formação e o Núcleo Curricular Básico previsto pela Multieducação (SME/RJ, 1996).

O Núcleo Curricular Básico Multieducação está relacionado a uma reforma educacional que teve como objetivo central a organização curricular das escolas da SME/RJ. Em 1996, o documento do Núcleo Curricular Básico Multieducação foi encaminhado a toda Rede da SME/RJ. Os pressupostos da Multieducação, se mantém orientando as escolas da SME/RJ, apesar de algumas descontinuidades administrativas, desde a sua criação. Incluem-se nesses pressupostos "lidar com os múltiplos universos que se encontram na escola” buscando a unidade na diversidade e a necessidade constante de atualização curricular, em consonância com as Diretrizes Curriculares Nacionais que se incluíam nos Parâmetros Curriculares Nacionais (PCNs) (BRASIL, 1997) em seus Princípios Éticos, Estéticos e Políticos (SME/RJ, p. 108). 


\section{O estudo de caso do PEA na escola da rede SME/RJ}

A escola da SME/RJ que serviu de lócus da pesquisa, atendia além do PEA, turmas do Ciclo de Formação do Ensino Fundamental, da Educação Infantil e em seu prédio anexo assistia crianças órfãs através de moradia e alimentação. Em 2007, quando se deu a pesquisa de campo, a escola havia sido selecionada pela SME/RJ para receber uma das classes do PEA. Como mencionado anteriormente o horário de atendimento às classes regulares era de 4 hs em dois turnos, enquanto da classes do PEA o horário era integral e em dois dias por semana se estendia até às $17 \mathrm{hs}$.

Duas salas de aula foram objeto de observação nesta escola, uma do $1^{\circ}$ ano do $1^{\circ}$ Ciclo de aprendizagem, correspondente a Classe de Alfabetização (CA) e a outra do PEA. Os dados, objeto de análise desse capítulo, restringem-se aos coletados através da observação participante, documentos e diálogos entre a equipe de pesquisa e os atores da escola que se constituíram enquanto sujeitos da pesquisa.

$\mathrm{O}$ acesso e a permanência na escola se deu por um processo de negociação constante com a Direção da Unidade, com os professores voluntários e outros atores escolares envolvidos na pesquisa. Entre momentos de recuo e avanços nas negociações sobre como desenvolver o projeto proposto para a pesquisa, firmou-se que os instrumentos de pesquisa limitar-se-íam às observações nessas turmas CA e PEA, a coleta de materiais e documentos disponibilizados pelos professores e pela escola e conversas informais sobre temas como as classes do Ciclos e do PEA com os diversos atores escolares que se dispusessem a fazê-lo. Não foi possível, como previsto, utilizar gravadores e câmeras para a obtenção de registros em áudio e vídeo durante a realização de entrevistas, participação nos Conselhos de Classe, reuniões de pais e de professores. As visitas foram limitadas a dois membros da equipe de pesquisa, que poderiam observar as classes juntos, durante duas horas por dia, duas vezes por semana, em dias e horários previamente combinados com os professores e a direção da escola. 
O período de observação limitou-se, então, a quatro meses entre março e junho de 2007. Após esse período o estudo de campo foi interrompido, tendo em vista que o processo de colaboração entre a equipe de pesquisa e os atores escolares não se pautou pelos pressupostos estabelecidos pela equipe para o desenvolvimento da pesquisa. Isto é, a colaboração estabelecida para o desenvolvimento precisa ser produtiva para ambos e as limitações impostas por parte da escola evidenciou que isto não aconteceria.

Foram sujeitos da pesquisa um total de 67 alunos, 47 da Classe do $1^{\circ}$ Ciclo e 20 do PEA, e dois professores colaboradores, o professor do PEA, a professora da Classe de Ciclo, além de pais e responsáveis, funcionários da escola e outras pessoas que pudessem nos fornecer informações sobre os alunos e espaço do PEA e da escola. No PEA, analisado nessa pesquisa, o professor era do sexo masculino, fato relevante, pois a maioria dos regentes de turma na SME/RJ eram do sexo feminino. Considerou-se como sujeitos primários todos os participantes que contribuíram com as fontes primárias de informações para a pesquisa, isto é, os alunos. Eles são os sujeitos primários porque são capazes de fornecer dados relevantes para se compreender o objeto de estudo, a classe do PEA, dos quais são também atores primários. Considerou-se como sujeitos secundários aqueles que auxiliaram na compreensão, classificação e confirmação dos dados que diretamente informavam sobre os sujeitos primários.

A maior parte dos 20 alunos do PEA, era originária da própria escola os outros alunos, eram originários das escolas 'vizinhas'.

As questões de pesquisa que guiaram as análises realizadas para este capítulo foram: Como o PEA foi conduzido? Quem eram os sujeitos do PEA? Como era a relação da classe do PEA com as demais classes da escola? Qual era a natureza do processo pedagógico construído na classe do PEA? Como esse processo poderia contribuir para o processo de ensino aprendizagem de adolescentes em risco educacional? 
As análises foram conduzidas pelo método indutivo, tendo como premissa principal as percepções e inferências dos atores sociais participantes da pesquisa, seguida a interpretação pela equipe de pesquisa que foi subsidiada por teorias pertinentes aos temas derivados da mesmas. A triangulação dos dados foi realizada, sempre que possível, utilizando fontes distintas de dados como documentos (fichas dos alunos, projetos, lista de chamada, atividades em xerox distribuídas pelos professores), anotações derivadas das observações, conteúdo da falas dos sujeitos primários e secundários, perspectivas teóricas debatidas durante o Seminário Permanente de Pesquisa (SPP) com membros da equipe e alunos da UERJ e mapas conceituais estudados no SPP sobre o tema.

\section{A Classe do PEA: formas de organização.}

Como dito anteriormente, a Classe do PEA era a única da escola com a carga horária ampliada, de $7 \mathrm{~h}$ às $15 \mathrm{~h}$, exceto às sextas-feiras quanto os alunos eram liberados às 11:45h. Dia da semana em que o professor da turma teria que se reunir com a Equipe da SME/RJ e com os demais professores regentes de outras classes do PEA Projeto. Os objetivos dessas reuniões eram: trocar informações sobre o andamento da projeto; receber orientações; assistir palestras; debater com os colegas estratégias pedagógicas, dentre outros, etc. Nas terças e quintasfeiras a turma se dividia em dois grupos, que eram atendidos alternadamente em um horário especial, das $15 \mathrm{~h}$ às $17: 15 \mathrm{~h}$, dentro da própria sala de aula.

Os alunos dessa turma possuíam dois recreios, o primeiro coincidindo com o do Ensino Fundamental e o segundo com a saída de todas as turmas do primeiro turno. Durante os intervalos, a escola oferecia almoço e lanche.

A escola como um todo, trabalhava o currículo com os temas transversais utilizando a técnica de projetos que eram desenvolvidos ao longo do ano. A Classe de PEA adotava também essa técnica, além das estratégias do projeto pedagógico específico para o PEA (SME/RJ, 2007). 
Essa classe estava preparada para receber até trinta alunos, como consta na Ementa do PEA (2007), porém em julho de 2007, a turma possuía vinte alunos matriculados. Desses alunos, quatorze frequentava as aulas, com muitas faltas. A turma era composta mais frequentemente por sete a dez alunos. Os registros de classe demonstravam que um total de seis deles eram oriundos da própria escola. Bianca, Enzo e Edmundo eram alunos originários do $3^{\circ}$ ano do $1^{\circ}$ Ciclo e ainda não haviam completado quatorze anos, enquanto Alexandre, Tatiane, João Marcelo eram originários da Classe de Progressão de 2006 e já haviam completado quatorze e quinze anos em 2007.

A sala de aula, era bastante ampla, assim como as outras salas da escola, porém mal iluminada e úmida. As paredes da sala eram brancas, com algumas manchas redondas de terra, como se alguém tivesse chutado uma bola contra elas. Havia na sala dois ventiladores que costumavam ficar ligados durante as aulas, um de teto e outro móvel com um tripé bem alto. Também havia uma televisão e um aparelho de som que eram usados com frequência pelos alunos na hora da entrada, enquanto 0 professor esperava o restante da turma chegar e também no recreio pelos alunos que preferiam permanecer em sala. Havia também na sala, dois armários com matérias didáticos como papel, cola, tesoura, cartolinas, dicionários e mais uma estante com livros de literatura infanto-juvenil e revistas de todos os tipos, inclusive revistas masculinas.

O uso de recursos tecnológicos era previsto pelo PEA como forma de dinamizar as aulas, fazendo uso de uma linguagem diferente, mais próxima dos interesses dos adolescentes (SME/ RJ 2007). Durante as observou-se que estes aparelhos eram usados, em geral, com o objetivo de entretenimento e por iniciativa dos alunos, o professor decidia sobre o momento em que eles deveriam utilizá-los.

A organização e disposição de cada aluno em sala de aula foi um importante elemento para se notar a dinâmica e movimento de desenvolvimento do PEA, inicialmente organizada em formato tradicional, enfileiradas, com o passar do tempo 
foi reorganizada em grupo. Como demonstrado nas figuras I e II abaixo:

Figura I

Sala de aula do PEA no início da atividades em 2007

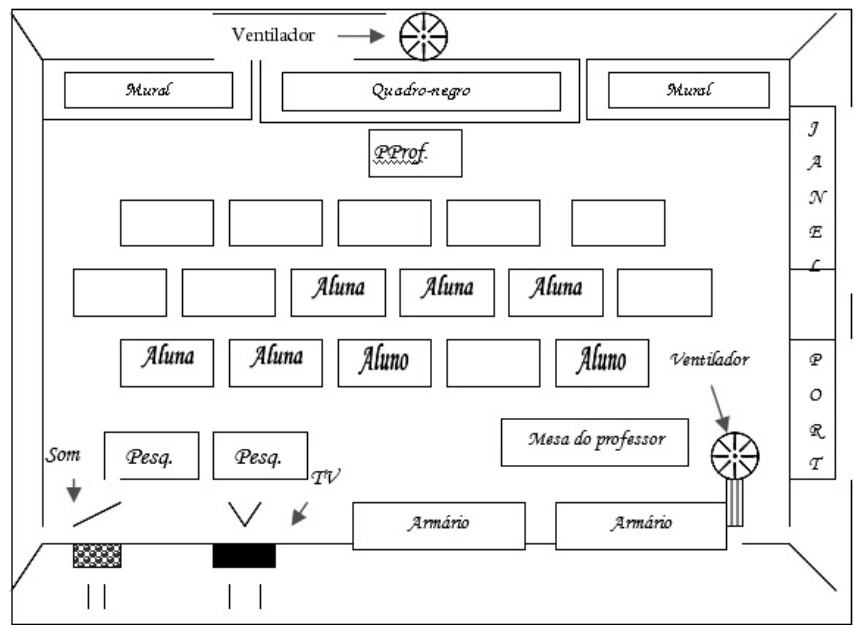

Fonte: Relatório II: Anotações de Campo do dia 16/04/2007 (FERREIRA; MATTOS, 2007).

\section{Figura II}

Sala de aula do PEA o $1^{\circ}$ mês de atividades em 2007

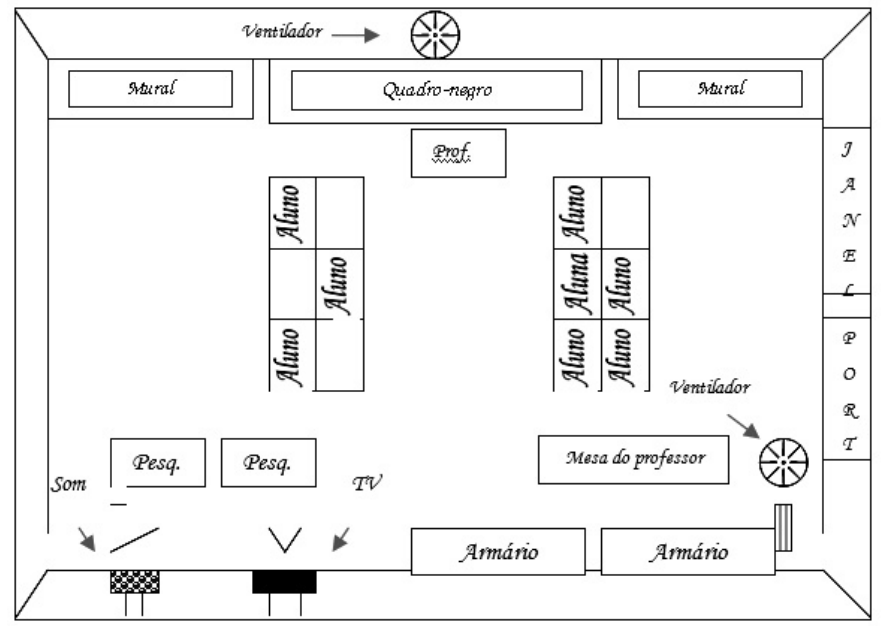

Fonte: Relatório VI: Anotações de Campo do dia 28/05/2007, (FERREIRA; MATTOS, 2007). 
Na organização, ilustrada no quadro I, os alunos sentavamse sempre a partir da segunda fileira e se agrupavam por conta própria. Nas semanas seguintes, o professor passou também a organizar as mesas dos alunos em dois grandes grupos Grupo II, alternando assim, o modelo anterior. Enquanto dava aula, o professor costumava se sentar à mesa que está mais próxima ao quadro-negro, dessa forma ele ficava voltado para a turma enquanto lia algum texto, explicava o dever ou promovia algum debate. Durante o tempo em que os alunos faziam as tarefas, ele se sentava à mesa que ficava próxima a porta. Quando se direcionava para o fundo da sala ele tinha uma visão de toda a turma enquanto aproveitava para fazer chamada, organizar seus papéis e o diário de classe.

A organização da sala no quadro I segue uma configuração tradicional onde as carteiras ficam dispostas uma atrás da outra em frete ao quadro-negro e onde o professor se posiciona em frente da turma para expor suas aulas (MATTOS; CASTRO, 2005). Nesse modelo os alunos tendem a centrar sua atenção na figura do professor. Já o quadro II indica um modelo onde a centralidade da atenção e volta para várias direções, em princípio, permite aos alunos, trocarem entre si, dúvidas e conhecimentos durante a elaboração das tarefas de aula, trabalho desenvolvido pela turma neste modelo passa então a ser realizado de modo coletivo.

No entanto, verificou-se que, em ambos modelos, a definição do espaço a ser ocupado em sala de aula pelos alunos, permitiria ao professor o controle e vigilância da movimentação dos alunos, uma vez que é o professor quem delimita a ocupação deste espaço (CASTRO, 2006).

A equipe de pesquisa sentava-se nas duas mesas ao fundo da sala de aula, o que permitia a observação de toda a turma e do professor. 


\section{A Classe do PEA: características das interações entre alunos, escola e professor-aluno.}

Para melhor entender como se dava o funcionamento da Classe do PEA é importante compreender como essa classe e os seus outros atores eram concebidos no âmbito escolar, assim como esta classe se relacionava com as demais da escola. Para isso, descrevemos algumas práticas observadas e o conteúdo do discurso existente no Projeto Político Pedagógico da Escola, dos professores, dirigentes e dos próprios alunos.

Verifica-se que a escola adotava em sua organização, modelos e práticas tradicionais comuns nas escolas públicas, isto é:

1) As salas de aula eram dispostas uma ao lado da outra até o fim do corredor, dentro delas as cadeiras estavam quase sempre enfileiradas e voltadas para quadro negro;

2) Os horários eram fracionados e delimitavam o momento em que os alunos deveriam entrar e sair da sala e da escola;

3) Todos os alunos deveriam usar o uniforme;

4) As relações estabelecidas pelos atores escolares eram permeadas por um regime de obediência hierárquica.

Para uma análise teórica buscou-se em Foucault (2002) justificativa para entender a necessidade da escola em manter procedimentos tradicionais quanto a organização física e pedagógica. Foucault (2002) afirma que a coação, o controle e a dominação pela disciplina se configuram como uma tecnologia pedagógica que atua diretamente sobre o corpo do indivíduo com o objetivo de transformá-lo em um corpo dócil (FOUCAULT, 2002, p. 127).

A Classe do PEA localizava-se ao fim de um corredor do prédio escolar, de frente para o pátio onde ocorria o recreio. Como a Educação Infantil e o Ensino Fundamental possuíam horários diferentes de recreio, o espaço o pátio era ocupado constantemente pelos alunos das outras turmas da escola. Para 
minimizar o barulho ocasionado pelos alunos em recreio, as janelas e portas da Classe do PEA permaneciam a maior parte do tempo fechadas, o que ocasionava um mau cheiro na sala, por conta da umidade. Com isso, chegamos à conclusão de que o local destinado pela escola à Classe do PEA era caracterizado pelo afastamento e pelo confinamento dos demais espaços da escola.

A chegada do PEA na escola trouxe incertezas, sobre o como e por quem esses alunos seriam atendidos, sobre como eles se encaixariam na rotina da escola no Projeto Político Pedagógico traçado para o desenvolvimento das atividades. Bauman (1999, p. 66) acredita que "na melhor das hipóteses a incerteza produz confusão e desconforto. Na pior, carregam um senso de perigo". E que a tendência mais comum de lidarmos com aquilo que é incerto é promovendo uma separação territorial e espacial, buscando reduzir a frequência desses problemas e “aliviar os aborrecimentos causados” (MATTOS, 1997).

O futuro dos alunos dessa Classe também era incerto para a escola, pois, uma vez que ela só atendia turmas até o primeiro segmento do Ensino fundamental, os alunos teriam que ser necessariamente encaminhados para outras escolas ao final do ano letivo de 2007. Inclusive os que já pertenciam à escola anteriormente.

Albuquerque (2004), acredita que os procedimentos de organização da escola são criações históricas e culturais de nosso tempo. Mas, que assim como a "síndrome dos objetos invisíveis” (GEERTZ, 2000, apud ALBUQUERQUE, 2004.) tais procedimentos estão tão obviamente diante dos nossos olhos, que é impossível encontrá-los. Ou seja, as relações estabelecidas dentro da escola são correntemente vistas como lógica e natural. Com isso, têm-se dificuldades em desnaturalizá-las e pensá-la de uma outra forma.

Uma prática da escola já bastante naturalizada é a obrigatoriedade do uso do uniforme. O uniforme pode ser considerado como sendo a tecnologia pedagógica que atua mais diretamente sobre o corpo do sujeito. Goffman (2000, p. 248), ao falar do uniforme usado nas prisões considera que "a roupa da prisão 
é anônima”. Tentando fugir do anonimato, alguns alunos da Classe do PEA tentavam imprimir sua individualidade através do uso de acessórios. As meninas usavam presilhas coloridas no cabelo, anéis, pulseiras, brincos, mochilas com chaveiros pendurados no zíper, blusinhas por baixo da camiseta do uniforme etc. Os meninos também costumavam complementar o uniforme com acessórios, e o mais usado por eles era o boné. Porém, a pedido da direção, o professor passou a proibi-los conforme pode ser ilustrado na cena abaixo:

O professor pede que Nadson tire o boné, ele então pergunta: "Porque isso agora?" o professor responde que são ordens da diretora. Nadson não obedece, o professor então pede que Enzo tire o boné. Enzo, a contragosto, acaba tirando (Relatório VI, anotações de campo do dia 28/05/2007, p.2).

Observou-se, durante a pesquisa, como era difícil a relação da Classe do PEA com a direção da escola. Não raro, o professor da Classe do PEA encaminhava alunos à secretaria pela falta de disciplina em sala de aula. Para o professor, a indisciplina se caracterizava pela desobediência às regras que ele havia estabelecido ou que foram estabelecidas em conjunto com a turma. Constituía-se como desobediência às regras: sair de sala durante a aula sem permissão, brigas, ofensas, brincadeiras fora de hora e o não cumprimento da tarefa.

Além de encaminhar os alunos desobedientes à direção, o professor também lançava mão de outras formas de punição, como mandar os alunos fazer cópias e enviar bilhetes aos responsáveis pedindo que eles comparecessem à escola:

Edmundo reclama que só recebe fora do professor e pergunta por que ele chamou sua tia na escola pra conversar. O professor responde que é porque ele já passou de todos os limites. (...) Edmundo continua preocupado com a visita de sua tia. Diz que ela ia estar lá hoje à tarde, o professor o interrompe e diz: 'Sorte sua que vai ter reunião' (Relatório IV, Anotações de campo do dia 18/05/2007, p. 2 e 4). 
Algumas vezes, a ameaça era feita sem que o professor dissesse qual castigo seria aplicado contra os alunos. O motivo pelo qual eles seriam castigados também não parecia ficar claro:

Juliana diz que está com febre, o professor manda-a ir lá fora beber água. Ela diz que não quer ir. Ele pergunta: Você vai me desobedecer?'. Ela responde que vai e ele diz: 'Então você vai ficar de castigo'. Bianca interfere: "Vem cá! Ela vai ficar de castigo só porque não quer beber água? Ai que agonia que isso me dá!' João Marcelo debocha: 'Tudo ele manda beber água!. (Relatório VI, anotações de Campo do dia 28/05/2007 p.3).

No interior da escola as ações dos alunos, do professor e da direção eram marcadas por uma relação de poder, que resultava num jogo em que um ora era oprimido, ora era opressor dentro de uma mesma lógica (FOUCAULT, 1978).

Segundo Freire (2006, p.48), essa opressão muitas vezes é mascarada por uma solidariedade que levará os oprimidos a 'serem mais', portanto, a escola ao punir o aluno desobediente às regras, estaria generosamente o disciplinando a ter um bom comportamento, ou a ter um comportamento que se espera que ele tenha. Assim, quem oprime, aos olhos dos opressores, são os oprimidos, que eles jamais obviamente chamam de oprimidos, mas de 'selvagens', 'violentos', bárbaros', 'malvados', quando reagem à violência da opressão. Freire (2006, p. 39-40) entende que a solidariedade exige de quem se solidariza que assuma a situação de com quem se solidarizou na busca pela liberdade, pois a solidariedade verdadeira implica em um agir com e não um agir para: "A liberdade é uma conquista e não uma doação, exige uma permanente busca. Busca permanente que só existe no ato de quem a faz. Ninguém tem liberdade para ser livre: pelo contrário, luta por ela precisamente porque não a tem” (p.37).

No mesmo caminho que Freire, Valle (2000, p.12) ao falar da construção da autonomia na prática educativa também se opõe ao modelo disciplinar e acrítico que a escola impõe aos alunos, explica eu ela acredita que a educação não deve ter 
como meta apenas socializar os indivíduos com base no que a sociedade institui de antemão, mas sim torná-los capaz de promover um novo modo de existência individual e coletiva.

A escola em seu Projeto Político Pedagógico, se declarava comprometida ir além do ensino de conteúdos para buscar uma construção de valores importantes à cidadania. No entanto o que ocorre no cotidiano escolar é uma prática naturalizada de coerção e de punição sem que os objetivos e os critérios fiquem claros para os alunos. O espaço para a deliberação e a legitimação dessas regras por parte dos sujeitos que a elas se impõe era restrito senão inexistente.

\section{Considerações finais}

A aproximação do contexto escolar permitiu evidenciar as regras, assim como a presença dos alunos nos classes do PEA não foram claramente compreendida pelos alunos e pela escola. Em relação a este fato Sampaio lembra que em uma escola "os alunos prejudicados têm rosto, nome, sonhos, histórias, não são números ou índices, assim como seus professores e suas professoras (SAMPAIO, 2000 p. 57). Os alunos do PEA nesta escola também o tinham mas eram como se não estivem ali, estavam resguardados, escondidos no final do corredor, numa sala de aula barulhenta e mau cheirosa em função da umidade e a proximidade com os banheiros.

Os índices do fracasso também exigem que se pense a realidade sobre quem fracassa. Quem fracassa na escola são pessoas. Essa constatação, muito longe de ser um discurso demagógico, também foi feita por Todorov (1995) - que descreveu a transformação de pessoas em não pessoas durante o regime nazista. Para ele a quantidade despersonifica e nos insensibiliza: "uma morte é uma dor, um milhão de mortos é uma informação”.

O regime escolar quase sempre é pautado pelo modelo da despersonificação, e isso ocorre de uma forma tão naturalizada que só a partir de um exercício muito grande que se consegue questioná-lo. Isso porque, na maioria das vezes, optamos pela uniformização e pela disciplina que retira, esconde o espaço da diversidade da diferença. 
O questionamento a esse regime, no entanto, revela que ele parece estar permanentemente contra o aluno e que alcançar o sucesso, significa vencer o sistema que a todo instante tenta empurra-lo para fora. A justificativa para a seleção promovida pela escola para a formação do grupo de alunos que se constituiu a classe do PEA, encontra respaldo na forma que para a sociedade significaria o sucesso, para ter sucesso é preciso enfrentar as barreiras, superar o outro o diferente. Portanto, dentro da escola o sucesso não é para muitos, assim como dentro da sociedade também não será, visto que no topo não há lugar para todos.

A reprovação, quase sempre esteve, aliada ao processo de exclusão, chegando a ser considerada uma prova de qualidade da escola e do professor. O bom professor era aquele que não 'deixava fácil', que reprovava até por décimos.

Por outro lado, quanto ao aluno a reprovação sempre esteve contra, sendo sinal de incompetência, incapacidade, preguiça etc. E por mais que ele ‘aprendesse a lição’ e não repetisse mais, ele ia carregar esse ano de atraso por toda a carreira escolar como uma marca de fracasso.

Com isso, a retirada da reprovação e a chegada dos Ciclos de Formação foi recebida tanto pela escola, quanto pela sociedade como o anúncio do caos. A escola que estava pautada na aprendizagem pelo medo da avaliação, da nota, da repetência e da humilhação, viu-se abalada.

A luta para a democratização ao acesso à escola exige uma transformação no sentido da educação por toda a sociedade, pois ela vai de encontro ao já naturalizado pensamento de que o acesso ao conhecimento é para poucos. Ou seja, frequentar a escola e avançar com sucesso é privilégio para apenas os que são fortes e determinados o suficiente ou que já recebem de herança familiar esse direito.

A democratização do acesso ao ensino ainda é um primeiro passo para que seja possível vislumbrar uma sociedade menos desigual, onde todos tenham consequentemente as mesmas possibilidades de acesso ao trabalho. 
Dentro da escola existe uma forte cultura que restringe o acesso ao saber. Mesmo com a implantação dos Ciclos, que no caso do Rio de Janeiro substituiu a reprovação do primeiro segmento do ensino fundamental até 2006 por relatórios de avaliação de progressão automática, embora as escolas continuassem a utilizar o modelo antigo retardando a reprovação para o final do $1^{\circ}$ segmento do Ciclo ou reprovando o aluno consecutivamente na Classe de Progressão, práticas que refletiram em parte na eliminação da mesma.

O fim da Progressão e a ampliação dos Ciclos em todo o ensino fundamental revelou que havia um contingente de alunos com idade entre quatorze e quinze anos que ainda não haviam passado do primeiro segmento, ou seja, ainda não tinha se quer sido se quer alfabetizado ou letrado de modo a poder dar continuidade aos estudos em outro nível.

O encontro com esses alunos na Classe do PEA possibilitado pela pesquisa, permitiu aos membros da equipe de pesquisa, entender um pouco mais como essa exclusão acontece dentro do espaço de sala de aula. O PEA que foi planejado para auxiliar o aluno, oferecendo uma maneira diferenciada de acompanhamento escolar com horário ampliado, formação continuada para o professor, dentre outros, acabou por encontrar os diversos entraves dentro da escola, que o levaram a reproduzir as mesmas práticas já naturalizadas no ambiente escolar, levando este aluno mais uma vez os alunos ao fracasso.

A falta de credibilidade no PEA e dos alunos que frequentavam esta classe, foi visível por parte da direção da escola e se refletiu na forma com que a Classe foi recebida por ela. Ela não só separou fisicamente a mesma das outras classes da escola, como ainda atribui a regência da Classe, por coincidência ou não, a um professor do sexo masculino, recém chegado o que para este representou uma 'prova de fogo' para sua entrada na rede pública de ensino.

Para Neubauer (2001), os Ciclos desvelam a incompetência da escola e do sistema em ensinar que a reprovação mascarava. Ele não permite mais que a punição seja unilateral e impede a farsa onde o professor "finge que ensina e o aluno 
não aprende porque não é capaz, pois no sistema de Ciclos a marca do fracasso não é mais do aluno, é da escola. Com isso, os Ciclos exigem o trabalho coletivo da escola para garantir o sucesso dos alunos, pois "a cada final de ano, ou o aluno conseguiu avançar mais, aprender, ou foi a escola que ficou para trás” (p. 10).

O movimento para a transformação que a autora afirma ocorra, advém de um processo lento das escolas. Professore, alunos e pais, lamentaram-se pelo fim da retenção, e continuaram a associar os baixos desempenhos dos alunos à retirada do estímulo que a possibilidade da reprovação garantia. No entanto, alguns estudos (WALLON, 1989; FREIRE, 2005; FERREIRO, 1995), já propunham um modelo escolar a favor da aprendizagem do aluno através de outros tipos de estímulos, como a valorização do saberes trazidos por eles, a atenção às suas curiosidades, entre outros, baseando-se em valores que permitem a troca, o respeito e a construção da autonomia do aluno.

A educação no país parece caminhar para significativas mudanças que, em grande parte, são conquistas de longas lutas impulsionadas principalmente por educadores progressistas, que através de seus trabalhos ou de sua capacidade de mobilizar a sociedade civil, conseguiram alcançar algumas melhorias nas Leis que regem a educação. No entanto, como a história educacional no Brasil é marcada por avanços e retrocessos, os Ciclos, assim como outras iniciativas tomadas como inovadoras, podem acabar se tornando apenas mais uma tentativa fracassada para que a democratização da educação aconteça. Neste sentido torna-se fundamental que haja uma compreensão desse tipo de proposta e a aprendizagem de uma postura sensível entre os profissionais da educação e o público em geral sobre o papel da escola nestas propostas. 


\section{Referências}

ANDRÉ, M. D. A. de. Estudo de caso em pesquisa e avaliação educacional. Brasília: Líber Livro, 2005.

ALBUQUERQUE, A. E. M. de. Educação e autoritarismo, por uma gestão democrática do espaço escolar. Revista Linhas Críticas, UnB, vol. 10, n. 18, p.33-48, jan./jun., 2004.

BAGNO, M. A Norma Oculta: língua \& poder na sociedade brasileira. $2^{a}$ ed. São Paulo: Parábola, 2003.

BAUMAN, Z. Modernidade e ambivalência. Rio de Janeiro: Jorge Zahar, 1999.

BRASIL. Lei de Diretrizes e Bases da Educação Nacional. Ministério da Educação: Brasília, DF. Disponível em:< http://portal.mec.gov.br/arquivos/pdf/ldb.pdf>. Acesso em: 14 junho 2008.

CARVALHO, M. P. de. Quem são os meninos que fracassam na escola? Cadernos de Pesquisa, v. 34, n. 121, p. 11-40, jan./abr., 2004.

CASTRO, P. A de. Controlar para quê? Um análise etnográfica da interação entre professor e aluno da sala de aula. 187f. 2006. Dissertação (Mestrado em Educação) - Faculdade de Educação, Universidade do Estado do Rio de Janeiro, Rio de Janeiro, 2006.

FAGUNDES, T. B. Fracasso Escolar: um estudo etnográfico em uma classe de progressão na rede pública do Rio de Janeiro. 2007. 84f. Monografia (Graduação em Pedagogia) - Faculdade de Educação, Departamento de estudos aplicados ao ensino, Universidade do Estado do Rio de Janeiro, Rio de Janeiro, 2007.

FERREIRO, E. Desenvolvimento da Alfabetização: psicogênese. In: GOODMAN, Y. M. (org). Como as crianças constroem a leitura e a escrita: perspectivas piagetianas. Porto Alegre: Artes Médicas, 1995.

FREIRE, P. Pedagogia do Oprimido. Rio de Janeiro, Paz e Terra, 2005. 
FOUCAULT, M. Microfísica do Poder. 25 ed. Rio de Janeiro: Edições Graal, 1979.

FOUCAULT, M. Vigiar e punir: nascimento da prisão. 26. ed. Petrópolis: Vozes, 2002.

GEERTZ, C. A interpretação das culturas. Rio de Janeiro: LTC, 1989.

GOFFMAN, E. Manicômios prisões e conventos. 7. ed. São Paulo: Perspectiva, 2001.

HAMMERSLEY, M.; ATKINSON, P. Ethnography: principles in practice. London: Routledge, 1983.

MATTOS, C. L. G de. Imagens etnográficas da inclusão: o fracasso escolar na perspectiva do aluno. Relatório de pesquisa Prociência (2005-2008). Universidade do Estado do Rio de Janeiro, 2008.

MATTOS, C. L. G. de; ALMEIDA, S. M. de; MELO, S. C de. O espaço da exclusão: o limite do corpo na sala de aula. Anais da Reunião Anual da ANPED, Caxambu - MG,1997.

MATTOS, C. L. G.; CASTRO, P. A. de. O uso de imagens de vídeo na pesquisa etnográfica. Anais IV Encontro de Pesquisa em Educação no Brasil / Região Sudeste - Educação: Direito ou Serviço? Belo Horizonte, 2005.

NEUBAUER, R. Quem tem medo da progressão continuada? Ou melhor, a quem interessa o sistema de reprovação e exclusão social? Publicação: Artigo da Secretaria Estadual de Educação, São Paulo, 2001. Disponível em: <http://www.centrofeducacional.com.br/progrcont.htm>. Acesso em: 14 junho 2008.

SME/RJ. Multieducação: refletindo sobre o trabalho no $1^{\circ}$ Ciclo de Formação. 2.ed. Secretaria Municipal de Educação do Rio de Janeiro Rio de Janeiro, Série: A Multieducação na Sala de Aula. 2007a. 
SME/RJ. Secretaria Municipal de Educação. Formação em Serviço para Professores Regentes do Projeto Especial Adolescentes 2007. Secretaria Municipal de Educação do Rio de Janeiro. Departamento Geral de Educação: Rio de Janeiro, 2007b.

SME/RJ. Secretaria Municipal de Educação. Os Ciclos do Ensino Fundamental, Aspectos Históricos, Políticos e Pedagógicos. Indicação n. ${ }^{\circ} 3 / 2007$. Secretaria Municipal de Educação do Rio de Janeiro: Rio de Janeiro, 2007c Disponível em: <http://www.rio. rj.gov.br/sme/downloads/cme/indicacao3.doc>. Acesso em: 16 junho 2008.

SAMPAIO, M. das M. F. Aceleração de Estudos: uma intervenção pedagógica. Em Aberto, Brasília v. 1, n.71, p. 57-73, jan. 2000.

TODOROV,T. Em face do extremo. Campinas: Papirus, 1995.

VALLE, L. do. Ensino de Filosofia - Perspectivas. Belo Horizonte: Autêntica, 2002.

WALLON, H. Origens do pensamento na criança. São Paulo: Nova Alexandria, 1989

SME/RJ. Núcleo Curricular Básico Multieducação. Secretaria Municipal de Educação do Rio de Janeiro. MULTIRIO: Rio de Janeiro,1996. 